\title{
Effect of Wnt-1 antisense RNA on the outgrowth of a mammary adenocarcinoma cell line expressing that oncogene
}

\author{
J Polanec, Z P Pavelic, W L Myers
}

\begin{abstract}
Aims-To investigate the effect of Wnt-1 antisense RNA on the outgrowth of a mammary tumour cell line expressing that oncogene.

Methods-A plasmid (pMT 70), containing Wnt-1 cDNA, was cut with appropriate enzymes and inserted into a eukaryotic expression vector (pMAMneo). A mammary tumour cell line (CAC-L153) was transfected with the expression vector and cells with the vector in sense and antisense orientation were selected.

Results-Tumour cells with the expression vector in the antisense orientation had a notable reduction in expression of Wnt-1 protein and a considerable reduction in tumour outgrowth compared with controls.

Conclusions-The results indicate that the Wnt-1 proto-oncogene may be a possible target for antisense therapy.

(F Clin Pathol: Mol Pathol 1996;49:M166-M169)
\end{abstract}

Keywords: mammary adenocarcinoma, cell lines, Wnt-1 oncogene, RNA.

Mouse mammary tumour virus (MMTV) induces mammary tumours in several strains of mice by insertion at crucial sites in the cellular genome. ${ }^{1}$ This insertional mutagenesis activates cellular proto-oncogenes by using the long terminal repeat (LTR) region of MMTV to alter expression of the nearby protooncogene. The first gene identified as an MMTV activated proto-oncogene was int $-1 .^{2}$ The gene was later renamed Wnt-1 because it encodes a secretory protein similar to that produced by the Drosophila wingless gene. ${ }^{3}$ The Wnt-1 gene is located on mouse chromosome 15 and like the progenitors of viral oncogenes, has been conserved during evolution. ${ }^{4}$ In the mouse, Wnt-1 is expressed normally only in round spermatids of adult testes and the neural tube of midgestation embryos. ${ }^{5}$

The Wnt-1 gene encodes a 36000 molecular weight product. This protein and three others with molecular weights ranging from 38000 to 42000 can be found in cells with Wnt-1 activation. The three larger proteins represent different glycosylated forms of the 36000 precursor. A monoclonal antibody directed against Wnt-1 peptide $A$ has been found to immunoprecipitate all four protein species from cell extracts. ${ }^{6}$ The Wnt-1 gene encoded glycoproteins enter the secretory pathway ${ }^{7}$ and while the cellular function of Wnt-1 is largely unknown, its role during embryogenesis has been studied. Inactivation of the Wnt-1 gene by homologous recombination results in loss of an entire area composed of most of the midbrain and part of the metencephalon. ${ }^{8}$

In order to support the hypothesis that Wnt-1 plays a significant role in MMTV induced mammary tumorigenesis, a number of groups have investigated the transforming effects of the gene on mammary epithelial cells. When mammary epithelial cells are infected with a recombinant retrovirus expressing Wnt-1, they undergo striking morphological changes, unrestricted growth at high cell density, and focus formation when grown as a monolayer. However, the cells were not tumorigenic in vivo. ${ }^{9}$ If a cloned mammary tumour cell line of low tumorigenicity is transfected with a Wnt-1 expression construct, there is a pronounced morphological transformation of the cells that is well correlated with Wnt-1 expression. The transformed cells are highly tumorigenic. ${ }^{10}$ Using transgenic mice carrying a Wnt-1 allele and expressing high levels of Wnt-1 RNA in mammary and salivary glands, it has been possible to show that all female mice and some male mice develop systemic mammary hyperplasia and, subsequently, focal mammary tumours. The tumour formation was accelerated by pregnancy. ${ }^{11}$

We were interested to understand what role Wnt-1 expression might be playing in the in vivo growth potential of the transformed mammary tumour cells. To investigate the biological functions of a gene product, it is usual to rely on naturaily occurring mutants of the gene. The in vitro generation of such gene mutants is restricted by the diploid nature of most genes and the difficulty of mutant selection. The use of antisense RNA expression provides a means of generating phenocopies of a null mutation of the targeted gene and thus assessing its contribution to cell phenotype. ${ }^{12}{ }^{13}$ While it is also possible to inhibit gene products with short pieces of DNA (oligodeoxynucleotides), they seem to work by many mechanisms, of which gene mRNA sequence specific binding by antisense DNA is one. ${ }^{14}{ }^{15}$ Thus, if one wishes to study the biological role of a selected gene by antisense application of a targeted oligodeoxynucleotide, the experimental design and interpretation of results becomes much more complex than that for antisense RNA. In the present study we examined the effects of 
antisense RNA from a Wnt-1 plasmid construct on the expression of the Wnt-1 gene in a mouse mammary epithelial tumour cell line.

\section{Methods}

CELLS

CAC-Li 53 cells with dexamethasone inducible Wnt-1 expression were kindly provided by R Nusse (Stanford University Medical Center, Stanford, California, USA). This cell line, which was isolated from a mammary adenocarcinoma transplanted in a $\mathrm{C} 3 \mathrm{H}$ mouse, has been characterised previously. ${ }^{16}$ Cells were cultivated in DMEM supplemented with $10 \%$ fetal bovine serum, $10 \mu \mathrm{g} / \mathrm{ml}$ insulin, and antibiotics at $37^{\circ} \mathrm{C}$ in a $5 \% \mathrm{CO}_{2}$ atmosphere. When Wnt-1 expression was required, 0.4 $\mu \mathrm{g} / \mathrm{ml}$ dexamethasone was added.

\section{PLASMID CONSTRUCTION}

Plasmids containing the Wnt-1 encoding sequence cloned in the antisense or sense orientation were constructed as follows: the pMT 70 clone of the pSP6 vector with the Wnt-1 gene inserted in the BamHl site was obtained from the American Type Culture Collection (Rockville, Maryland, USA). The gene was cut out with EcoRI and HindIII and inserted into pBluescript II KS vector (Stratagene, LaJolla, California, USA). This construct was used to obtain the Wnt-1 gene with Xbal restriction consisting of one Xbal site derived from the polylinker segment of pSP6 and the other Xbal site from the pBluescript polylinker. The Xbal cut insert was inserted into the Nhel site of pMAMneo expression vector (Clontech, Palo Alto, California, USA) which has a dexamethasone inducible promoter. The orientation of the clones was determined by Clal digestion.

DNA TRANSFECTION

The CAC-L153 cell line was transfected with either sense or antisense plasmid constructs by using liposome mediated delivery (Lipofectin Reagent, Gibco-BRL, Gaithersburg, Maryland, USA). Transfected tumour cells were grown in complete medium for 72 hours before the addition of selection medium. Transfectants were selected for resistance to medium containing up to $400 \mu \mathrm{g} / \mathrm{ml}$ Geneticin (G418 sulphate). After 30 days of culture in selection medium, drug resistant cells were cloned by limiting dilution in selective medium.

In order to demonstrate that CAC-L153 cells transfected with the antisense plasmid were genuinely producing antisense mRNA for the Wnt-1 gene, a ribonuclease protection assay was carried out. A cRNA probe was synthesised using $5 \mu \mathrm{g}$ linearised plasmid and $200 \mu \mathrm{Ci}\left[{ }^{32} \mathrm{P}\right]$ cytidine triphosphate. The pBluescript II KS-, containing the Wnt-1 gene as a HindIII/EcoR 1 fragment, was linearised and transcribed with $\mathrm{T} 3$ polymerase to yield a 240 nucleotide long sense transcript containing the 5' region of the Wnt-1 gene, the complete exon 1 (104 nucleotides) and 47 nucleotides of the T3 polylinker site.

The specific activity of the probe was $7 \times 10^{8}$ $\mathrm{cpm} / \mu \mathrm{g}$. Either 10 or $30 \mu \mathrm{g}$ dried total RNA from the pMAMneo antisense transfected
CAC cell line or $30 \mu \mathrm{g}$ from the parental CAC cell line, extracted using a standard method, ${ }^{17}$ were mixed with the cRNA sense probe for the Wnt-1 gene $\left(1 \times 10^{6} \mathrm{cpm}\right)$ in $24 \mu \mathrm{l}$ deionised formamide and $6 \mu \mathrm{l} 5 \mathrm{x}$ hybridisation buffer. The mixtures were heated at $85^{\circ} \mathrm{C}$ for five minutes, and hybridised at $37^{\circ} \mathrm{C}$ for 12 hours. After hybridisation, the remaining single stranded RNA was digested with $14 \mu \mathrm{g}$ RNase $A$ and 100 units of RNase T1 in $350 \mu$ RNase digest buffer for one hour at $25^{\circ} \mathrm{C}$. RNase was then digested with $10 \mu \mathrm{l}$ of $10 \mu \mathrm{l} / \mathrm{ml}$ proteinase solution plus $20 \mu \mathrm{l}$ of a $10 \%$ SDS solution at $37^{\circ} \mathrm{C}$ for 30 minutes. Protein was then extracted with $200 \mu \mathrm{l}$ phenol and $200 \mu \mathrm{l}$ chloroform. RNA hybrids were precipitated from the aqueous phase in $1 \mathrm{ml} 100 \%$ ethanol after addition of $1 \mu \mathrm{l}$ yeast tRNA $(10 \mathrm{mg} / \mathrm{ml})$. The sample was centrifuged and the supernatant aspirated. The pellet was dried in a vacuum centrifuge and then resuspended in 10 $\mu$ l RNA loading buffer. Samples were heated at $85^{\circ} \mathrm{C}$ for five minutes, loaded onto a $6 \%$ polyacrylamide/ $8 \mathrm{M}$ urea sequencing gel and electrophoresed at 2500 volts for one hour. After electrophoresis, the gel was transferred to Whatman filter paper, dried under vacuum, and visualised using $x$ ray film and an intensifying screen at $-70^{\circ} \mathrm{C}$ for 12 hours.

WESTERN IMMUNOBLOTTING

Wnt-1 protein expression was evaluated using cell membrane preparations from control and transfected cells. Cell membranes were prepared by sonification of cells at a concentration of $10 \times 10^{6} / \mathrm{ml}$ in $50 \mu \mathrm{M}$ Tris buffer ( $\left.\mathrm{pH} 7.6\right)$ containing protease inhibitors, followed by centrifugation at $4000 \times g$ for 10 minutes in a microfuge. The pellet was resuspended in Tris buffer, and aliquots stored at $-70^{\circ} \mathrm{C}$ pending analysis. Standard SDS polyacrylamide gel electrophoresis, using a Proetean apparatus (BioRad), was carried out using a $12 \%$ resolving gel under reducing conditions and $50 \mu \mathrm{g}$ protein per lane. Proteins were transferred to nitrocellulose using a Tran-Blot SD apparatus (BioRad) run at approximately $3 \mathrm{~mA} / \mathrm{cm}^{2}$ for 30 minutes. The nitrocellulose membrane was then washed three times for 15 minutes in membrane blocking reagent (phosphate buffered saline containing $5 \%$ non-fat dried milk and $0.01 \%$ Tween 20 ) to remove the transblotting buffer and then blocked for one hour in the same reagent. After washing, blots were incubated overnight at $4^{\circ} \mathrm{C}$ with a 1 in 10 dilution of a hybridoma culture supernatant containing monoclonal antibodies directed against Wnt-1 peptide A (kindly provided by A Brown, Cornell University Medical College, New York, New York, USA). A control without the primary antibody was also run. After incubation with the primary antibody, blots were rinsed and treated for one hour with $50 \mu \mathrm{Ci}$ rabbit-antimouse $\operatorname{lgG}-{ }^{125} \mathrm{I}$ (Dupont, Boston, Massachusetts, USA). The blots were rinsed again and then exposed to $x$ ray film overnight.

TUMOUR OUTGROWTH ASSAY

The growth rates of the original and transfected CAC cell lines were determined using five week old female $\mathrm{C} 3 \mathrm{H} / \mathrm{HeN}$ mice. Groups 


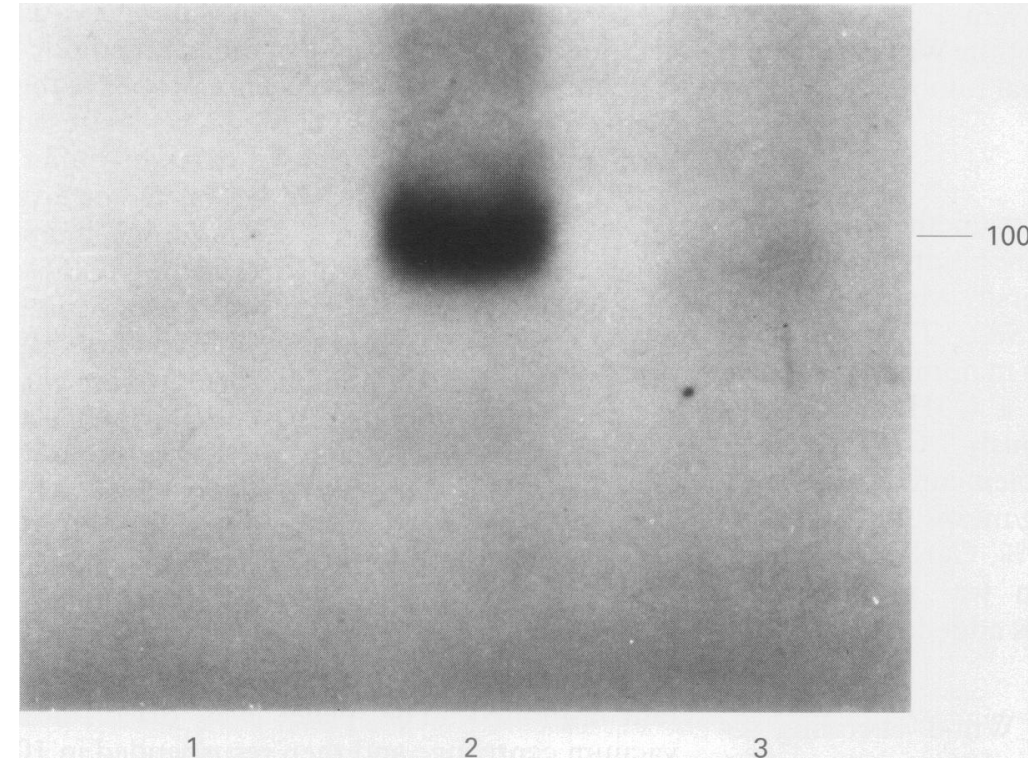

Figure 1 Ribonuclease protection assay. Lane 1,30 $\mathrm{mg}$ total RNA from untransfected CAC-L153 cells; lane 2, $30 \mathrm{mg}$ total RNA from CAC-L153 cells transfected with pMAMneo expression vector in antisense orientation with a protected $R N A$ band of 100 nucleotides in size (arrow); lane 3, as in lane 2 except $10 \mathrm{mg}$ total RNA was used.
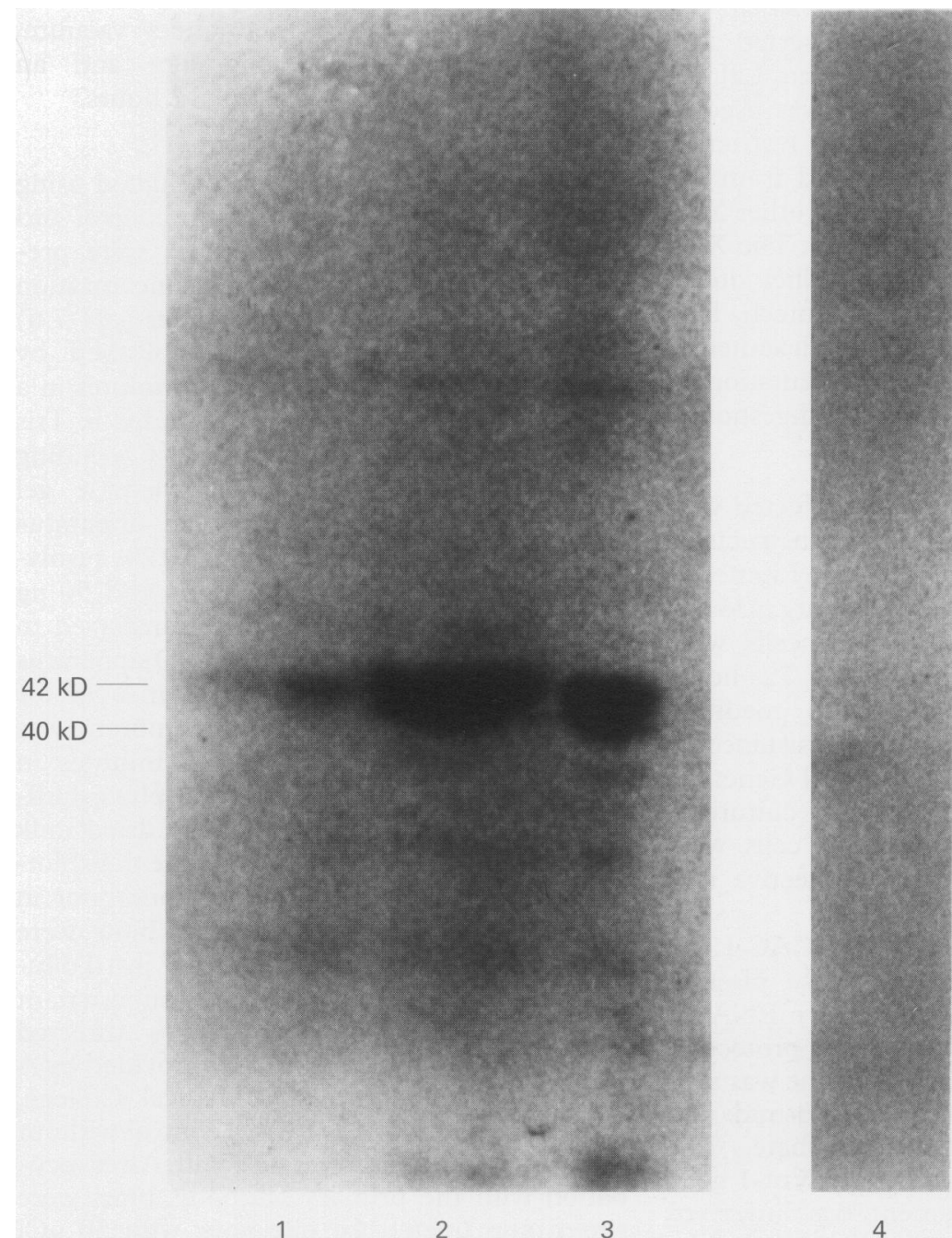

4

Figure 2 Western blot for Wnt-1 protein using $50 \mu \mathrm{g}$ extracted cell membrane protein per lane. Lane 1,CAC-L153 cells transfected with pMAMneo expression vector in antisense orientation; lane 2, as in lane 1 except in sense orientation; lane 3,CAC-L153 cells without transfection; lane 4, as in lane 3, but without incubation with primary antibody.

of 10 mice were each injected subcutaneously with $5 \times 10^{5}$ or $1.2 \times 10^{6}$ live cells for each control and treated group. Tumour outgrowth was monitored at one week intervals by serial measurements of two perpendicular tumour diameters with Vennier calipers. The data are reported as group mean tumour diameter in $\mathrm{mm} \pm \mathrm{SEM}$. The significance of any differences between groups was determined by $t$ statistics for two independent means.

\section{Results}

RIBONUCLEASE PROTECTION ASSAY

Transcription of antisense Wnt-1 mRNA was confirmed in the ribonuclease protection assay using total RNA from transfected clones of CAC-L153 cells. A protected RNA fragment of approximately 100 nucleotides was the major band detected in the total RNA from the antisense pMAMneo transformants (fig 1, lanes 2 and 3). This band corresponds closely with the length of the exon 1 region of the Wnt-1 gene used in the cRNA sense probe. No bands were detected using the total RNA from untransfected CAC-L153 cells (fig 1, lane 1).

WESTERN IMMUNOBLOTTING FOR DETECTION OF WNT-1 PROTEINS

The expression of Wnt-1 protein products was found to be noticeably diminished in cellular extracts from antisense pMAMneo transformants (fig 2, lane 1) compared with cellular extracts from sense transfected and nontransfected CAC-L153 cells (lanes 2 and 4, respectively). The two Wnt-1 proteins detected here with apparent molecular weights of 40 and 42 kilodaltons represent glycosylated derivatives of the 36 kilodalton precursor protein. When the blot of extract from CAC-L153 cells was not treated with the primary antibody, no comparable protein bands were detected (fig 2, lanes 3 and 4).

TUMOUR OUTGROWTH ASSAY FOR CAC-L153 CELLS

The growth rate of CAC-L153 cells transfected with the pMAMneo expression vector containing Wnt-1 cDNA in antisense orientation was significantly reduced compared with untransfected CAC-L153 cells ( $p<0.01$ ) or CAC-L153 cells transfected with pMAMneo in sense orientation $(\mathrm{p}<0.01)$ at two, three and four weeks post-transplant (fig 3 ). The dose of CAC-L153 antisense transfected cells required to produce minimally detectable tumour growth in the fourth week was more than double $\left(5 \times 10^{5} v 1.2 \times 10^{6}\right)$ that for sense transfected or untransfected cells. Even with a dose of $1.2 \times 10^{6}$ cells, antisense transfected cells had a latent period of at least three weeks for minimally detectable tumours. Tumours could be detected in animals injected with sense transfected or untransfected CAC-L153 cells within one week.

\section{Discussion}

We have shown that the down regulation of Wnt-1 expression significantly reduces the tumour outgrowth of mammary adenocarcinoma cells with this gene activation. These results are in agreement with other studies that have shown that one of the effects of antisense 

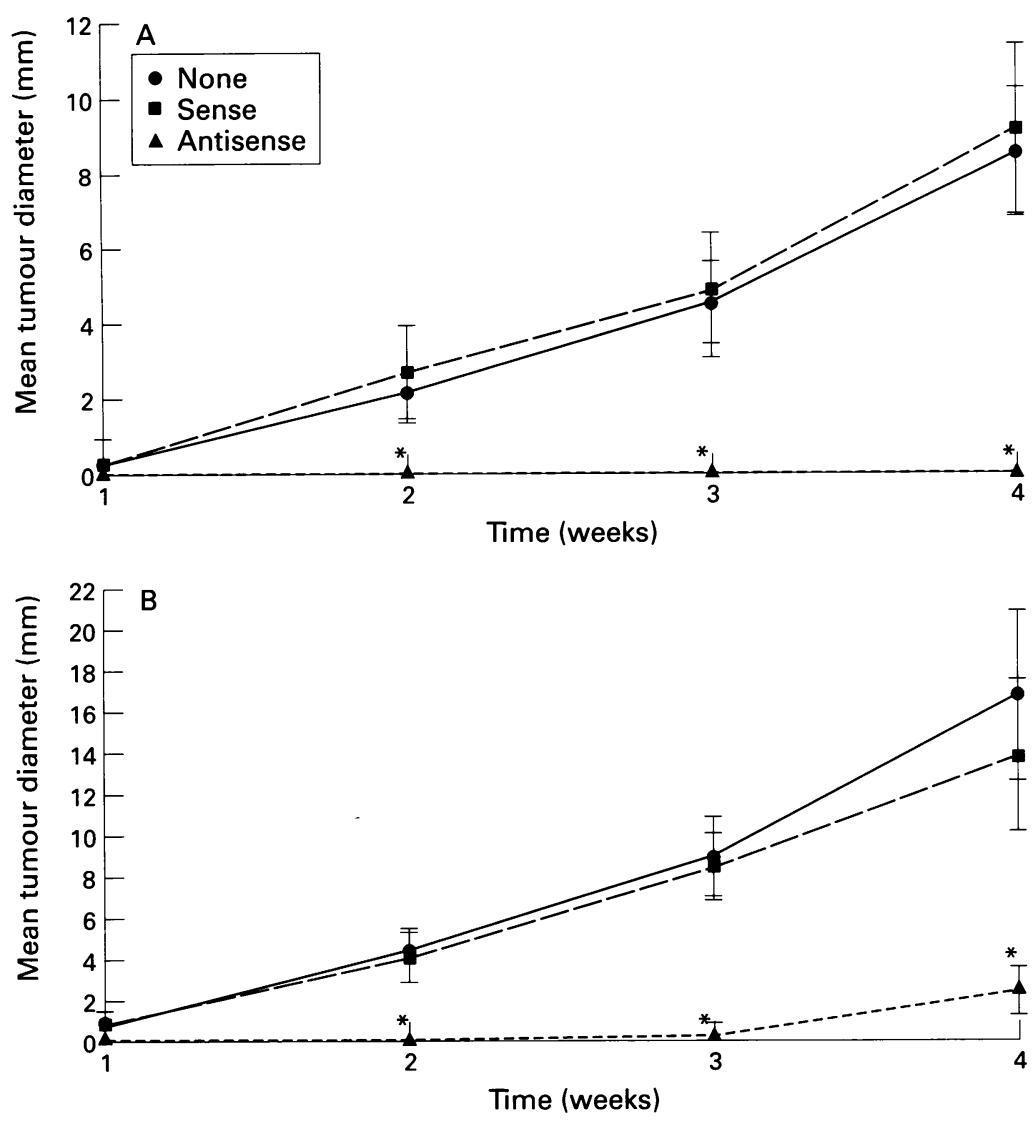

Figure 3 Growth of CAC-L153 control or transfected cells in vitro. Groups of 10 mice were each injected subcutaneously with either $5 \times 10^{5}(A)$ or $1.2 \times 10^{6}(B)$ of (sense or antisense) transfected or untransfected (none) CAC-L153 cells. At one week intervals the group mean tumour diameter \pm SEM (bars) was determined for each group and treatment. Significant differences $(p<0.01)$ between treatments are indicated by an asterisk.

RNA targeted to other activated oncogenes in transformed cells is to reduce tumorigenicity when the cells are transplanted..$^{13}$

More than one mechanism may be invoked in interpreting the role of the Wnt-1 gene in maintaining tumorigenicity. Wnt-1 protein may be a growth factor for mammary epithelial cells or it may down regulate the receptor for a negative growth factor, as proposed by Lin et $a l .{ }^{19}$ While the Wnt-1 protein is secreted, it seems to be bound to the cell membrane ${ }^{20}$ or extracellular matrix ${ }^{21}$ and probably has local effects in the mammary gland. In cells expressing Wnt-1 antisense RNA, the loss of growth advantage may lead to cell death resulting from apotosis or increased susceptibility to the cytotoxic effector mechanisms of the host. ${ }^{12}$

The failure of CAC-L153 antisense transfected cells to give rise to local tumour following subcutaneous injection with $5 \times 10^{5}$ live cells, but not $1.2 \times 10^{6}$ cells, suggests that the requirement for Wnt-1 expression can be overcome at higher cell densities. This ability of high cell numbers to produce tumours may depend on other cellular factors independent of Wnt-1 expression. An alternative explanation would be that as the antisense transfected cells still express residual levels of Wnt-1 protein (fig 2), higher cell densities produce sufficient Wnt-1 protein to sustain a small responsive subpopulation capable of tumour formation. This alternative explanation is supported by the observation that the animals injected with $1.2 \times 10^{6}$ antisense transfected cells had much longer latent periods before tumour appearance than animals injected with $1.2 \times 10^{6}$ untreated or sense transfected CACL153 cells.

New cancer treatments aimed at the specific down regulation of growth factors and other proteins produced by oncogenes are now underway. One of the promising targets for specific therapy is mRNA, the activity of which can be down regulated by using a RNA or DNA antisense strategy. Our data suggest that in tumour cells with Wnt-1 expression, the Wnt-1 oncogene may provide a specific target for effective antisense therapy.

1 Varmus HE. The molecular genetics of cellular oncogenes. Ann Rev Genet 1984;18:553-612.

2 Nusse R, Varmus J. Many tumors induced by the mouse mammary tumor virus contain a provirus integrated in the mammary tumor virus contain a provirus integrated in the

3 Nusse R, Brown A, Papkoff J, Scambler P, Shackleford G McMahon A, et al. A new nomenclature for int-1 and McMahon A, et al. A new nomenclature for int-1
related genes: The Wnt gene family. Cell 1991;64:231

4 Nusse R, van Ooyen A, Cox D, Fung YKT, Varmus H. Mode of proviral activation of a putative mammary oncogene (int-1) on mouse chromosome 15. Nature 1984; 307:131-5.

5 Shackleford GM, Varmus H. Expression of the protooncogene int-1 is restricted to postmeiotic male germ cells and the neural tube of mid-gestational embryos. Cell 1987;50:89-95.

6 Brown AMC, Papkoff J, Fung YKT, Shackleford GM, Varmus HE. Identification of protein products encoded by Varmus HE. Identification of protein products encoded by

7 Papkoff J, Brown AMC, Varmus HE. The int-1 protooncogene products are glycoproteins that appear to ente the secretory pathway. Mol Cell Biol 1987;7:3978-84.

$8 \mathrm{McM}$ ahon AP, Bradley A. The Wnt-1 (int-1) protooncogene is required for development of a large region of the mouse brain. Cell 1990;62:1073-85.

9 Brown AMC, Wildin RS, Prendergast TJ, Varmus HE. A retrovirus vector expressing the putative mammary oncogene int-1 causes partial transformation of a mammary epithelial cell line. Cell 1986;46:1001-9.

10 Rijsewijk F, van Deemter L, Wagenaar E, Sonnenberg A Nusse R. Transfection of the int-1 mammary oncogene in cuboidal RAC mammary cell line results in morphological transformation and tumorigenicity. EMBO $₹$ 1987;6:127transfor

11 Tsukamoto A, Grosschedl R, Guzman RC, Parslow R, Varmus HE. Expression of the int-1 gene in transgenic mice is associated with mammary gland hyperplasia and adenocarcinoma in male and female mice. Cell 1988 55:619-25.

12 Long L, Rubin R, Baserga R, Brodt P. Loss of the metastatic phenotype in murine carcinoma cells expressing an antisense RNA to the insulin-like growth factor receptor. Cancer Res 1995;55:1006-9.

13 Reed JC, Cuddy M, Haldar S, Croce C, Nowell P, Makover D, Bradley K. BCL2-mediated tumorigenicity of a human D-lymphoid cell line: synergy with MYC and inhibition by T-lymphoid cell line: synergy with MYC and inhibition by

14 Chrisey LA, Pazirandeh M, Liss HS. Nonsequence-specific inhibition of bacterial luminescence by phosphorothioate oligodeoxyribonucleotides. Antisense Res Dev 1995 5:261-9.

15 Jansen B, Wadl H, Inove SA, Trülzsch B, Selzer E, Duchêne $\mathrm{M}$, et al. Phosphorothioate oligonucleotides reduce melanoma growth in a SCID-hu mouse model by a nonantisense mechanism. Antisense Res Dev 1995; 5:271-7.

16 Schuuring E, van der Leede BJ, Willems R, Daams $H$, van der Valk $M$, van der Vijver $M$, et al. Differentiationdependent expression of provirus-activated int-1 oncogene in clonal cell lines derived from a mouse mammary tumor. in clonal cell lines derived

17 Sambrook J, Fritsch EF, Maniatis R. Extraction, purification, and analysis of messenger RNA from eukaryotic cells. In: Nolan C, ed. Molecular cloning: a laboratory manual. New York: Cold Spring Harbor Laboratory Press, 1989:7.6-7.9.

18 Kasid U, Pfeifer A, Brennan T, Beckett M, Weichselbaum RR, Dritschilo A, Mark GE. Effect of antisense c-raf-1 on tumorigenicity and radiation sensitivity of a human squamous carcinoma. Science 1989;234:1354-6.

19 Lin TP, Guzman RC, Osborn RC, Therdarson G, Nandi S. Role of endocrine, autocrine, and paracrine interactions in Role of endocrine, autocrine, and paracrine interactions in the development of mammary hyperplasia in

20 Papkoff J, Schryver B. Secreted int-1 protein is associated with the cell surface. Mol Cell Biol 1990;10:2723-30.

21 Bradley RS, Brown AMC. The proto-oncogene int-1 encodes a secreted protein associated with the extracellular matrix. EMBO f 1990;9:1569-75. 